\title{
Production of proinflammatory cytokines and myocardial dysfunction after arterial switch operation in neonates with transposition of the great arteries
}

\author{
Hedwig H. Hövels-Gürich, MD ${ }^{a}$ \\ Jaime F. Vazquez-Jimenez, $M D^{b}$ \\ Anna Silvestri ${ }^{\mathrm{a}}$ \\ Kathrin Schumacher ${ }^{\mathrm{a}}$ \\ Ralf Minkenberg ${ }^{\mathrm{C}}$ \\ Jean Duchateau, MD ${ }^{\mathrm{d}}$ \\ Bruno J. Messmer, MD \\ Götz von Bernuth, MD \\ Marie-Christine Seghaye, MD $^{\mathrm{a}}$
}

From the Departments of Pediatric Cardiology $^{\mathrm{a}}$ and Thoracic and Cardiovascular Surgery $^{\mathrm{b}}$ and the Institute of Biomedical Statistics, ${ }^{\mathrm{c}}$ Aachen University of Technology, Aachen, Germany, and the Department of Immunology, ${ }^{\mathrm{d}}$ Hôpital Brugman, Brussels, Belgium.

Received for publication May 25, 2001; revisions requested Oct 16, 2001; revisions received Nov 9, 2001; accepted for publication Dec 10, 2001.

Address for reprints: Hedwig H. HövelsGürich, MD, Department of Pediatric Cardiology, Aachen University of Technology, Pauwelsstr 30, D-52057 Aachen, Germany (E-mail: hhoevels-guerich@ukaachen.de).

J Thorac Cardiovasc Surg 2002;124:811-20

Copyright $(9) 2002$ by The American Association for Thoracic Surgery

0022-5223/2002 $\$ 35.00+0 \quad \mathbf{1 2 / 1 / 1 2 2 3 0 8}$

doi:10.1067/mtc.2002.122308

Objective: Neonates undergoing cardiac surgery have a systemic inflammatory reaction with release of proinflammatory cytokines, which could be responsible for myocardial dysfunction as a result of myocardial cell damage. The purpose of this study was to test the hypothesis that the production of proinflammatory cytokines during cardiac surgery would be associated with myocardial dysfunction after the arterial switch operation in neonates.

Methods: A total of 63 neonates with transposition of the great arteries were operated on with combined deep hypothermic circulatory arrest and low-flow cardiopulmonary bypass at a median age of 7 days. Perioperative plasma concentrations of interleukins 6 and 8 were correlated with myocardial dysfunction, as assessed clinically and by echocardiography within 24 hours after the operation, and with perioperative cardiac troponin $\mathrm{T}$ blood levels as a marker of myocardial cell damage.

Results: Myocardial dysfunction was observed in 11 patients (17.5\%), and 2 of them died. Durations of cardiopulmonary bypass and aortic crossclamping, but not of circulatory arrest, were correlated with myocardial dysfunction. Patients with myocardial dysfunction had significantly higher cardiac troponin $\mathrm{T}$ blood levels at the end of cardiopulmonary bypass and 4 and 24 hours after the operation than did patients without myocardial dysfunction. Patients with myocardial dysfunction also had higher interleukin 6 plasma concentrations after cardiopulmonary bypass and 4 hours after the operation, as well as higher interleukin 8 plasma concentrations 4 and 24 hours after the operation, than did those without myocardial dysfunction. Postoperative interleukin 6 and 8 plasma concentrations were significantly correlated with postoperative cardiac troponin T blood levels. Multivariable analysis of independent risk factors for myocardial dysfunction comprising cytokine and troponin levels and bypass duration revealed interleukin 6 levels 4 hours after the operation as significant $(P=.047)$.

Conclusions: Cardiac operations in neonates stimulate the production of proinflammatory cytokines, which may contribute to myocardial cell damage and myocardial dysfunction. 


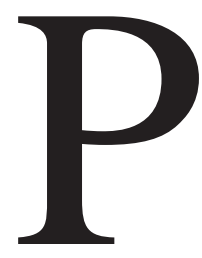

erioperative myocardial damage is an important factor influencing postoperative course and hemodynamic profile after surgery for congenital heart disease, ${ }^{1-5}$ but its pathophysiologic mechanisms remain unclear. The systemic and intramyocardial inflammatory response has been suggested to contribute to myocardial dysfunction. ${ }^{6,7}$

Term neonates undergoing cardiac surgery have a systemic inflammatory reaction comprising complement activation, leukocyte stimulation, and cytokine synthesis. ${ }^{8,9}$ Proinflammatory cytokines such as interleukin (IL) 6, the regulator of the acute-phase response, and IL-8, a potent chemokine with neutrophil-stimulating properties, are involved in the systemic inflammatory response related to cardiopulmonary bypass (CPB) in children. ${ }^{10-13}$ These cytokines may cause myocardial cell damage and consecutive myocardial dysfunction as a result of nitric oxide-independent and nitric oxide-dependent pathways ${ }^{14-16}$ and as a result of increased leukocyte-endothelial cell interactions, with consequent capillary obstruction and impaired microcirculation in the myocardium. ${ }^{17}$

Although the responsibility of perioperative proinflammatory cytokine production for the development of postoperative myocardial dysfunction has been suggested in adult patients after cardiac surgery, ${ }^{18-21}$ this question has never been addressed in children or neonates. It was therefore the aim of our study to test the hypothesis that proinflammatory cytokine release during cardiac surgery in neonates is associated with postoperative myocardial cell damage and consequent myocardial dysfunction.

\section{Methods \\ Clinical Data}

Patients. After approval by the human ethical committee of our institution and informed consent of the parents, 63 consecutive term neonates aged 2 to 28 days (median 7 days, interquartile difference 6 days) at surgery were included in this prospective study. Patients' demographic data are shown in Table 1. The inclusion criterion was transposition of the great arteries, with a ventricular septal defect (VSD) suitable for the arterial switch operation or without (no VSD, $\mathrm{n}=53$ ), with closure of the VSD if necessary (VSD closure, $\mathrm{n}=10$ ). Coronary artery status was categorized as normal (types $\mathrm{A} 1$ or $\mathrm{AB} 1$ ) or abnormal (other types), according to the classification of Gittenberger-de Groot and associates. ${ }^{22}$ All patients received prostaglandin $\mathrm{E}_{1}$ infusion $(0.05$ $\mu \mathrm{g} /[\mathrm{kg} \cdot \min ])$ before the operation to maintain patency of the ductus arteriosus. Maternofetal infection or bacterial infection before the operation and preoperative organ dysfunction were cause for exclusion in all cases.

Anesthesia and antibiotic regimen. Conventional general anesthesia was conducted with diazepam, fentanyl sulfate, and pancuronium bromide. After induction of anesthesia, nasotracheal intubation was performed in the patients not receiving ventilatory support, and central venous catheters and peripheral arterial cath- eter were inserted. Perioperative antibiotic prophylaxis consisted of cefotiam. Dexamethasone was given before sternotomy at a dosage of $3 \mathrm{mg} / \mathrm{m}^{2}$ body surface area.

Cardiopulmonary bypass protocol. The CPB circuit included a roller pump, a disposable membrane oxygenator, and an arterial filter. Cooling and rewarming were carried out with a heat exchanger. The priming solution consisted of a crystalloid solution, mannitol (3 mL/kg), and leukocyte-depleted packed red blood cells to obtain a hematocrit value of the circulating volume of about $25 \%$. Heparinization was achieved with heparin sulfate $(3 \mathrm{mg} / \mathrm{kg})$. For vasodilatation in the cooling and rewarming periods, all neonates received a continuous infusion of sodium nitroprusside (SNP, 0.5-1 $\mu \mathrm{g} /[\mathrm{kg} \cdot \mathrm{min}])$. CPB was instituted with a perfusion index of $2.7 \mathrm{~L} /\left(\mathrm{min} \cdot \mathrm{m}^{2}\right)$, which was maintained throughout the cooling phase. During CPB the pH-stat method was used, with correction of $\mathrm{PaO}_{2}$ to the patients's hypothermic temperature to maintain a $\mathrm{pH}$ value of 7.40. After deep hypothermia was reached (minimal nasopharyngeal temperature averaging $15^{\circ} \mathrm{C}$ ), aortic crossclamping was done and cardioplegia was induced with a single intra-aortic injection of a $4^{\circ} \mathrm{C}$ cold Bretschneider solution (30 mL/kg), and cardiocirculatory arrest was instituted for a target period of not longer than 60 minutes. The surgical procedure was continued under low-flow perfusion ( $25 \%$ of the calculated initial perfusion rate). Rewarming was achieved under full-flow conditions. The lungs of the neonates were reventilated when core temperature reached $30^{\circ} \mathrm{C}$. Neutralization of heparin was achieved with protamine sulfate in a 1:1 ratio. Epinephrine, dopamine, and SNP were systematically administered for weaning the patients from CPB. After coronary reperfusion and at the end of the operation, intraoperative myocardial function was assessed by the cardiac surgeon, as explained here. In cases of hemodynamic instability or myocardial dysfunction at the end of the operation, sternal closure was delayed until stabilization, and sternal wounds were closed with a latex membrane.

Perioperative and postoperative care. Postoperative monitoring included continuous registration of heart rate and rhythm, arterial blood pressure, central venous pressure, and diuresis. Target values for mean arterial blood pressure, central venous pressure, and diuresis during the first 72 hours after the operation were $45 \mathrm{~mm} \mathrm{Hg}, 5$ to $7 \mathrm{~mm} \mathrm{Hg}$, and more than $1.5 \mathrm{~mL} /(\mathrm{kg} \cdot \mathrm{h})$, respectively. Inotropic support, vasodilation, and diuretic treatment consisting of epinephrine, dopamine, dobutamine, SNP, and furosemide were adapted accordingly, as was volume substitution, which was carried out with fresh-frozen plasma or 5\% human albumin. Blood gas values, serum electrolytes, serum creatinine, aspartate aminotransferase (AST), and bilirubin were routinely measured during the first 3 postoperative days. The ratio between $\mathrm{PaO}_{2}$ and inspired oxygen fraction was used as oxygenation index for patients receiving ventilatory support.

Myocardial dysfunction was considered to be hypocontractility of one or both ventricles, as reported by the surgeon at the end of the operation or by the pediatric cardiologist from systematic transthoracic echocardiography 4 and 24 hours after the operation. Repeated routine transesophageal echocardiography was not possible in most cases. The decision to delay sternal closure or increase inotropic support was based on hemodynamic parameters, as stated previously, and was not a criterion for assignment to the myocardial dysfunction group. 
Myocardial ischemia was diagnosed in the presence of discolored or demarcated myocardial areas seen by the surgeon after coronary reperfusion and before the end of the operation. It was also diagnosed on the basis of typical repolarization abnormalities in the standard electrocardiogram 4 and 24 hours after the operation.

Total inotropic support was calculated 4 and 24 hours after the operation by adding the doses of dopamine and dobutamine in micrograms per kilogram per minute and assigning an arbitrary equivalent value of $10 \mu \mathrm{g} /(\mathrm{kg} \cdot \min )$ inotropic agent for each 0.1 $\mu \mathrm{g} /(\mathrm{kg} \cdot \min )$ epinephrine. ${ }^{1}$ Dopamine was given in a dosage of $5 \mu \mathrm{g} /(\mathrm{kg} \cdot \mathrm{min})$ as basic support in all cases. Dobutamine was administered at a dosage of 5 to $10 \mu \mathrm{g} /(\mathrm{kg} \cdot \min )$, according to hemodynamic need, and epinephrine was given additionally, also according to hemodynamic need.

\section{Specific Laboratory Examinations}

Collection of samples. Venous blood was collected before and after the operation. During CPB, blood was withdrawn from the arterial line of the circuit. For each sample time, $1 \mathrm{~mL}$ blood was taken in tubes containing ethylenediaminetetraacetic acid. The samples were immediately centrifuged for 3 minutes (3000 rpm), and the plasma was stored at $-70^{\circ} \mathrm{C}$ until analysis. Plasma samples were collected before the operation, at the end of CPB after protamine administration, and at 4 and 24 hours after the end of CPB.

Cardiac troponin T. Cardiac troponin T (cTnT) concentration was determined by enzyme-linked immunosorbent assay (ELISA Troponin-T Kit; Boehringer Mannheim, Division of Roche Pharmaceuticals, Mannheim, Germany), with the use of two highly specific monoclonal antibodies directed against two different epitopes of the cTnT molecule, allowing high specificity. Crossreactivity with skeletal muscle troponin $\mathrm{T}$ and the influence of hemolysis and hyperbilirubinemia (bilirubin $<25 \mathrm{mg} / \mathrm{dL}$ ) were excluded by the manufacturer. Normal values for healthy neonates range up to $0.33 \mathrm{ng} / \mathrm{mL}$ (95th percentile according to Panteghini and associates $\left.{ }^{23}\right)$.

Cytokines. IL-6 and IL-8 concentrations were measured by immunoenzymetric assay (enzyme-amplified sensitivity immunoassay; BioSource Europe [formerly Medgenix Diagnosics], Nivelles, Belgium) according to the manufacturer's recommendation. This is a solid-phase enzyme-amplified sensitivity immunoassay performed on microtiter plate that is based on the oligoclonal system in which several monoclonal antibodies directed against distinct epitopes of the intact cytokine are used, allowing high sensitivity of the assay. The minimal detectable concentrations are $2 \mathrm{pg} / \mathrm{mL}$ for IL- 6 and $0.7 \mathrm{pg} / \mathrm{mL}$ for IL- 8 . The ranges covered by the standard curve are 0 to $2100 \mathrm{pg} / \mathrm{mL}$ for IL- 6 and 0 to 750 $\mathrm{pg} / \mathrm{mL}$ for IL-8. In plasma from healthy adults, values range between 0 and $70 \mathrm{pg} / \mathrm{mL}$ for IL- 6 and between 0 and $47 \mathrm{pg} / \mathrm{mL}$ for IL-8. In cord venous and arterial blood from healthy neonates, mean $( \pm$ SEM) values are $16 \pm 2$ and $40 \pm 14 \mathrm{pg} / \mathrm{mL}$, respectively, for IL- 6 and $4.6 \pm 1.0$ and $6.1 \pm 1.0 \mathrm{pg} / \mathrm{mL}$, respectively, for IL-8 according to our previous results. ${ }^{24}$

During the study period, cTnT, IL-6, and IL-8 plasma levels were not known to the treating physicians.
TABLE 1. Demographic data and duration of perfusion variables related to myocardial dysfunction

\begin{tabular}{|c|c|c|c|}
\hline & $\begin{array}{c}\text { Myocardial } \\
\text { dysfunction } \\
\text { (n=11; 17.5\%) }\end{array}$ & $\begin{array}{l}\text { No myocardial } \\
\text { dysfunction } \\
\text { (n = 52; } 82.5 \%)\end{array}$ & $P$ value* \\
\hline \multicolumn{4}{|l|}{ VSD status (No.) } \\
\hline VSD closure & 5 & 5 & .01 \\
\hline No VSD & 6 & 47 & \\
\hline \multicolumn{4}{|l|}{ Coronary status (No.) } \\
\hline $\begin{array}{l}\text { Normal (types } A 1 \\
\text { and } A B 1) \dagger\end{array}$ & 10 & 42 & $>.2$ \\
\hline $\begin{array}{l}\text { Abnormal (other } \\
\text { types) } \dagger\end{array}$ & 1 & 10 & \\
\hline \multicolumn{4}{|l|}{ Operative variables } \\
\hline $\begin{array}{l}\text { Age at operation } \\
\text { (d, median and } \\
\text { interquartile } \\
\text { difference) }\end{array}$ & $9(8)$ & $7(5)$ & .07 \\
\hline $\begin{array}{l}\text { CPB (min, median } \\
\text { and interquartile } \\
\text { difference) }\end{array}$ & $55(41)$ & $45(15)$ & .03 \\
\hline $\begin{array}{l}\text { Aortic } \\
\text { crossclamping } \\
\text { (min, median } \\
\text { and interquartile } \\
\text { difference) }\end{array}$ & $78(26)$ & $62(9)$ & .008 \\
\hline $\begin{array}{l}\text { DHCA (min, } \\
\text { median and } \\
\text { interquartile } \\
\text { difference) }\end{array}$ & $60(6)$ & $59(4)$ & $>.2$ \\
\hline
\end{tabular}

${ }^{*}$ Calculated by Fisher exact test (parametric variables) or Mann-Whitney $U$ test (nonparametric variables) for the effect of the demographic and perfusion parameters, stratified for myocardial dysfunction or no myocardial dysfunction.

tCoronary artery status according to Gittenberger-de Groot et al. ${ }^{22}$

\section{Statistical Analysis}

Results are expressed as the median value and interquartile range or interquartile difference, assuming nonnormal distribution of the data, or by their logarithmic values. For intergroup comparison of clinical and biologic variables at specific sample times, the nonparametric Mann-Whitney $U$ test was used. For comparison of biologic variables at specific sample times within a group, the paired nonparametric Wilcoxon test was used. The Spearman rank correlation coefficient was assessed for correlation of independent parameters, and the Fisher exact test was used for the analysis of contingency tables. The $\alpha$ adjustment for repeated measures was done according to the Bonferroni-Holm method. For multivariable analysis of risk factors for the occurrence of myocardial dysfunction within 24 postoperative hours, a logistic regression was performed with nine independent risk factors that were statistically significant in corresponding univariate analysis: VSD closure, CPB duration, aortic crossclamping duration, IL-6 blood levels 4 hours after the operation, IL- 8 blood levels 4 and 24 hours after the operation, and cTnT blood levels at the end of CPB and 4 and 24 hours after the operation. Additional case-matched analysis for the 
TABLE 2. Clinical outcome data related to myocardial dysfunction

\begin{tabular}{|c|c|c|c|}
\hline & $\begin{array}{c}\text { Myocardial } \\
\text { dysfunction } \\
(\mathrm{n}=11)\end{array}$ & $\begin{array}{l}\text { No myocardial } \\
\text { dysfunction } \\
\text { (n = 52) }\end{array}$ & $P$ value* \\
\hline \multicolumn{4}{|l|}{ AST (U/L, median and interquartile difference) } \\
\hline 4 postoperative $\mathrm{h}$ & $70(98)$ & $32(18)$ & .003 \\
\hline 24 postoperative $\mathrm{h}$ & $84(103)$ & $16(15)$ & .003 \\
\hline \multicolumn{4}{|l|}{ Oxygenation index† (median and interquartile difference) } \\
\hline 4 postoperative $h$ & $140(147)$ & $193(104)$ & $>.2$ \\
\hline 24 postoperative $\mathrm{h}$ & $177(156)$ & $220(125)$ & .05 \\
\hline \multicolumn{4}{|l|}{$\begin{array}{l}\text { Total inotropic support }(\mu \mathrm{g} /[\mathrm{kg} \cdot \mathrm{min}] \text {, median and } \\
\text { interquartile difference) }\end{array}$} \\
\hline 4 postoperative $\mathrm{h}$ & $26.6(42.4)$ & $13.6(17.3)$ & .04 \\
\hline 24 postoperative $\mathrm{h}$ & $53.8(40.1)$ & $8.8(14.5)$ & $<.001$ \\
\hline \multicolumn{4}{|l|}{ SNP $(\mu \mathrm{g} /[\mathrm{kg} \cdot \min ]$, median and interquartile difference) } \\
\hline 4 postoperative $h$ & $0.93(0.61)$ & $0.99(0.65)$ & $>.2$ \\
\hline 24 postoperative $\mathrm{h}$ & $1.00(0.68)$ & $0.87(0.40)$ & $>.2$ \\
\hline Delayed sternal closure (No.) & 5 & 0 & $<.001$ \\
\hline $\begin{array}{l}\text { Postoperative mechanical ventilation (h, median and } \\
\text { interquartile difference) }\end{array}$ & $130(70) \ddagger$ & $96(72)$ & .04 \\
\hline In-hospital death (No.) & $2 \S$ & 0 & .02 \\
\hline
\end{tabular}

*Calculated by Fisher exact test (parametric variables) or Mann-Whitney $U$ test (nonparametric variables) for the effect of the outcome variables, stratified for myocardial dysfunction or no myocardial dysfunction.

tRatio between partial arterial oxygen tension and inspired oxygen fraction in patients with mechanical ventilation.

$\ddagger \mathrm{n}=9$.

§Patient 1, with subpulmonary VSD and normal coronary anatomy, had left ventricular infarction after coronary reperfusion and died 25 hours after the operation. Patient 2, with large inlet-type VSD and abnormal coronary anatomy, had right ventricular infarction after coronary reperfusion and died 35 hours after the operation.

durations of CPB and aortic crossclamping was performed in order to evaluate whether cytokine plasma levels were different in patients for whom $\mathrm{CPB}$ and aortic crossclamping durations were similar but in whom myocardial dysfunction did or did not develop. Statistical analysis was performed with the Statistical Analysis System, version 8.0 (SAS Institute, Inc, Cary, NC). The term significant was used to indicate statistical, not clinical, significance.

\section{Results}

\section{Clinical results}

Two of 63 patients $(3.2 \%)$ died within the early postoperative period (Table 2). Eleven neonates (17.5\%) had myocardial dysfunction develop within the first 24 hours after CPB (5 patients at the end of the operation and 6 patients in the postoperative period), according to the clinical definition given previously. Four of these neonates also had signs of myocardial ischemia ( 2 of them died). In 5 cases the sternum was left open at the end of the operation.

According to the univariate analyses, patients with myocardial dysfunction had longer CPB and aortic crossclamping durations than did those without myocardial dysfunction, whereas differences in duration of deep hypothermic cardiac arrest (DHCA) could have been due to chance (Table 1). Patients with VSD closure had significantly longer durations of CPB (median $75 \mathrm{~min}$, interquartile difference $30 \mathrm{~min}$, vs median $44 \mathrm{~min}$, interquartile difference
$14 \min , P=.03$ ) and of aortic crossclamping (median 82 min, interquartile difference $13 \mathrm{~min}$, vs median $62 \mathrm{~min}$, interquartile difference $7 \mathrm{~min}, P=.008$ ) than did those without myocardial dysfunction. Myocardial dysfunction was significantly more frequent in patients with VSD closure than in those without such closure. Age at surgery tended to influence the occurrence of myocardial dysfunction. Differences in coronary artery status with respect to myocardial dysfunction could have been due to chance (Table 1).

With respect to perioperative hemodynamic data 4 and 24 hours after the operation, median arterial blood pressure, central venous pressure, and diuresis were not different in patients with and without myocardial dysfunction $(P>.2$ each; data not shown), whereas AST was significantly elevated 4 and 24 hours after the operation and oxygenation index tended to be lower 24 hours after the operation in patients with myocardial dysfunction. Total inotropic support was significantly higher 4 and 24 hours after the operation in patients with myocardial dysfunction than in those without myocardial dysfunction, whereas differences in SNP dosages could have been due to chance. Delayed sternal closure after severe intraoperative hemodynamic instability was more frequent and mechanical ventilation time was prolonged in patients with myocardial dysfunction (Table 2). 


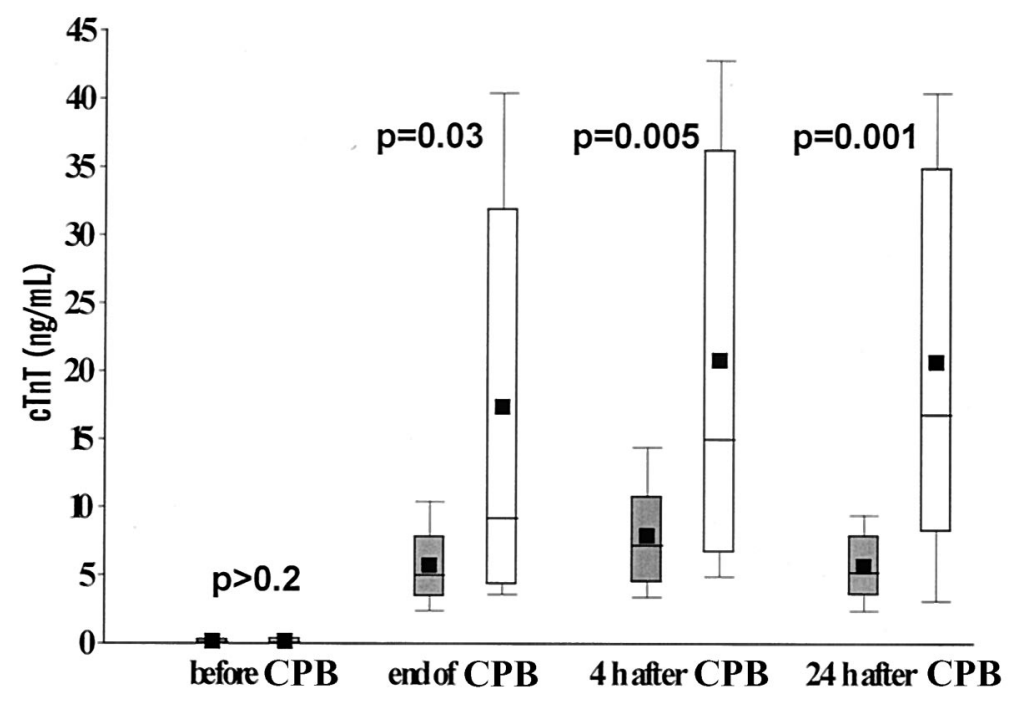

Figure 1. Concentrations of cTnT related to presence (white bars, $n=11$ ) and absence ( shaded bars, $n=52$ ) of myocardial dysfunction after CPB in 63 patients. Values expressed as mean (data points), median (horizontal lines), interquartile ranges (bars), and 10th and 90th percentiles (error bars). $P$ values represent differences between subgroups with and without myocardial dysfunction.

\section{Cardiac Troponin T}

Preoperative cTnT levels were normal in all neonates except for two $(0.4$ and $0.9 \mathrm{ng} / \mathrm{mL})$, in whom neither preoperative, perioperative, nor postoperative complications, nor findings of myocardial dysfunction, were present. Within the whole group as well as within the subgroups with and without myocardial dysfunction, cTnT levels rose significantly at the end of $\mathrm{CPB}$, reaching peak values 4 hours after the operation $(P<.001$ each vs preoperative values; Figure 1$)$. The cTnT levels fell between 4 and 24 hours after the operation $(P<.001$ each). The cTnT values after CPB were significantly correlated with those 4 and 24 hours after the operation (Figure 2); cTnT values after CPB, 4 and 24 hours after the operation were correlated with durations of CPB and aortic crossclamping but not DHCA (Table 3). Intergroup comparison between patients with and without myocardial dysfunction showed significantly higher cTnT levels in patients with myocardial dysfunction at the end of CPB and 4 and 24 hours after the operation than in those without myocardial dysfunction (Figure 1).

\section{Interleukin 6}

In all neonates, preoperative IL-6 levels were not markedly elevated relative to either normal adult or cord blood values. Within the whole group, as well as within the subgroups with and without myocardial dysfunction, IL-6 levels rose significantly at the end of CPB; peak levels were reached 4 hours after the operation in patients with myocardial dysfunction and 24 hours after the operation in patients without myocardial dysfunction $(P<.001$ each vs preoperative values; Figure 3). IL-6 values after CPB were correlated with durations of $\mathrm{CPB}$, aortic crossclamping, and DHCA (Table 3). Significant correlations were found between IL-6 and cTnT levels after CPB (Spearman correlation coefficient $0.32, P=.02$ ). Intergroup comparison between patients with and without myocardial dysfunction showed that IL-6 levels tended to be higher at the end of CPB and were significantly higher 4 hours after the operation in patients with myocardial dysfunction than in those without myocardial dysfunction (Figure 3).

\section{Interleukin 8}

In all neonates, preoperative IL-8 levels were not markedly elevated relative to either normal adult or cord blood values. Within the whole group, as well as within the subgroups with and without myocardial dysfunction, IL-8 levels rose significantly at the end of $\mathrm{CPB}$, reaching peak values 4 hours after the operation $(P<.001$ each vs preoperative values; Figure 4), and decreased 24 hours after the operation. IL-8 values after $\mathrm{CPB}$ were correlated with durations of CPB, aortic crossclamping, and DHCA (Table 3). Significant correlations were found between IL-8 and cTnT levels 4 hours after the operation (Spearman correlation coefficient $0.34, P=.02$ ), between IL-8 levels 4 hours after the operation and cTnT levels 24 hours after the operation (Spearman correlation coefficient $0.46, P=.001$ ), and between IL-8 levels and cTnT levels 24 hours after the operation (Spearman correlation coefficient $0.43, P=.003$ ). Intergroup comparison between patients with and without myocardial dysfunction showed significantly higher IL-8 


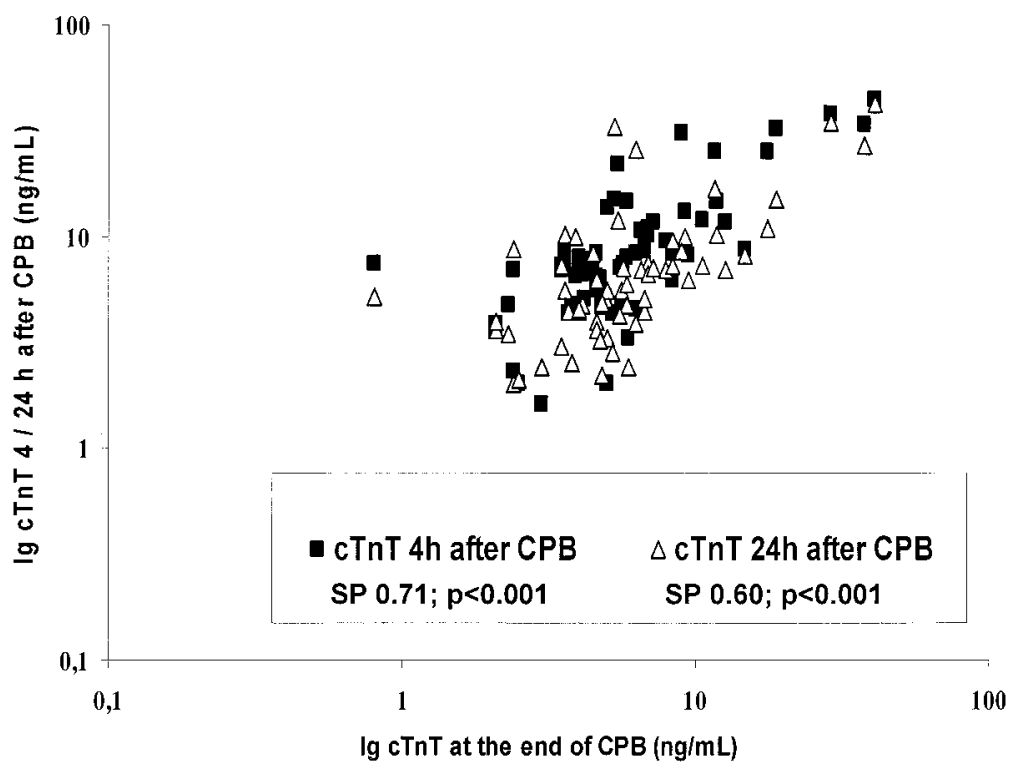

Figure 2. Correlations between cTnT values at end of CPB with those 4 (squares, Spearman correlation coefficient $0.71, P<.001$ ) and 24 (triangles, Spearman correlation coefficient $0.60, P<.001$ ) hours after operation in 63 patients. All parameters are expressed by their logarithmic values.

TABLE 3. Concentration of cTnT, IL-6, and IL-8 related to perfusion variables $(n=63)$

\begin{tabular}{|c|c|c|c|c|c|c|}
\hline & \multicolumn{2}{|c|}{ CPB (min) } & \multicolumn{2}{|c|}{ Aortic crossclamping (min) } & \multicolumn{2}{|c|}{ DHCA (min) } \\
\hline & $\begin{array}{l}\text { Spearman } \\
\text { correlation } \\
\text { coefficient }\end{array}$ & $P$ value* & $\begin{array}{l}\text { Spearman } \\
\text { correlation } \\
\text { coefficient }\end{array}$ & $P$ value* & $\begin{array}{l}\text { Spearman } \\
\text { correlation } \\
\text { coefficient }\end{array}$ & $P$ value* \\
\hline \multicolumn{7}{|l|}{$\mathrm{cTnT}(\mathrm{ng} / \mathrm{mL})$} \\
\hline End CPB & 0.47 & $<.001$ & 0.49 & $<.001$ & 0.23 & 0.08 \\
\hline 4 postoperative $\mathrm{h}$ & 0.45 & $<.001$ & 0.44 & $<.001$ & 0.15 & $>0.2$ \\
\hline $\begin{array}{l}24 \text { postoperative } \mathrm{h} \\
\text { IL-6 (pg/mL) }\end{array}$ & 0.41 & .001 & 0.37 & .003 & 0.12 & $>0.2$ \\
\hline End CPB & 0.39 & .003 & 0.34 & .01 & 0.36 & .007 \\
\hline 4 postoperative $\mathrm{h}$ & 0.02 & $>.2$ & 0.14 & $>.2$ & 0.10 & $>.2$ \\
\hline $\begin{array}{l}24 \text { postoperative h } \\
\text { IL-8 (pg/mL) }\end{array}$ & -0.12 & $>.2$ & 0.10 & $>.2$ & 0.20 & .20 \\
\hline End CPB & 0.34 & .01 & 0.31 & .02 & 0.28 & .04 \\
\hline 4 postoperative $\mathrm{h}$ & 0.40 & .005 & 0.39 & .006 & 0.25 & .09 \\
\hline 24 postoperative $\mathrm{h}$ & 0.25 & .1 & 0.38 & .009 & 0.12 & $>.2$ \\
\hline
\end{tabular}

*Calculated by Spearman correlation coefficients.

levels in patients with myocardial dysfunction 4 and 24 hours after the operation than in those without myocardial dysfunction (Figure 4).

\section{Multivariable Analysis}

Multivariable analysis of independent risk factors for the occurrence of myocardial dysfunction within 24 hours after the operation was performed with nine parameters (VSD closure, CPB duration, aortic crossclamping duration, IL-6 blood levels 4 hours after the operation, IL- 8 blood levels 4 and 24 hours after the operation, and cTnT blood levels at the end of CPB and 4 and 24 hours after the operation), according to the model described previously. IL-6 plasma concentration 4 hours after the operation was evaluated as significant for prediction of myocardial dysfunction within 24 hours after the operation $(P=.047$, odds ratio per 10 $\mathrm{pg} / \mathrm{mL} 1.241,95 \%$ confidence interval, 1.002-1.535). The cutoff point for prediction of myocardial dysfunction was set at $500 \mathrm{pg} / \mathrm{mL}$ (specificity $95.4 \%$, sensitivity $72.7 \%$ ).

Additional case-matched analysis for the durations of 


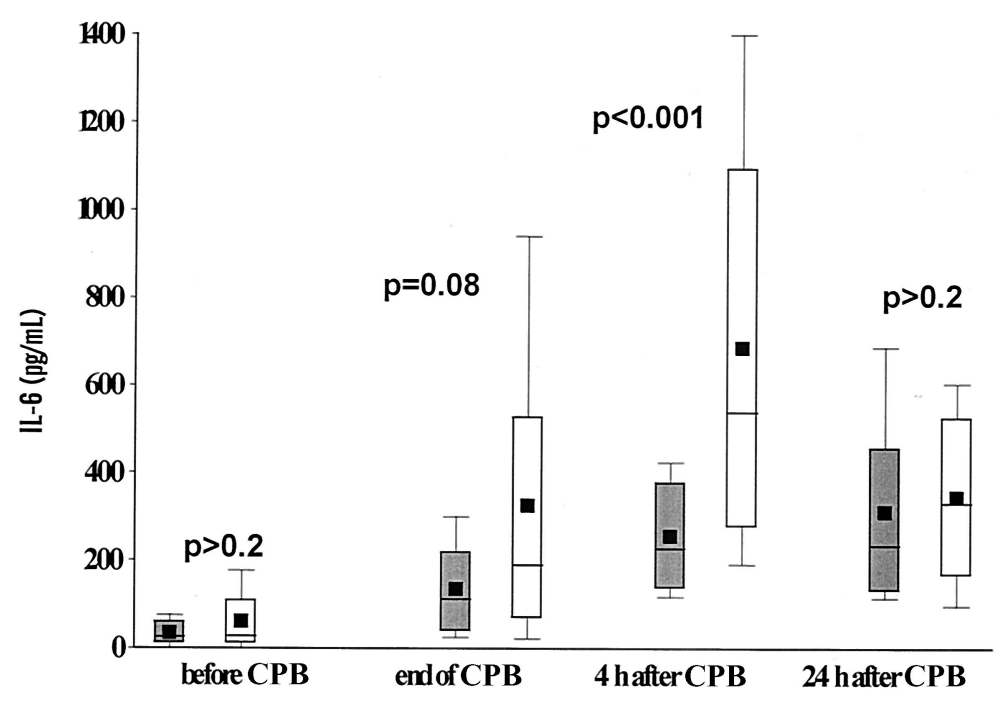

Figure 3. IL-6 levels related to presence (white bars, $n=11$ ) and absence (shaded bars, $n=52$ ) of myocardial dysfunction after CPB in 63 patients. Values expressed as mean (data points), median (horizontal lines), interquartile ranges (bars), and 10th and 90th percentiles (error bars). $P$ values represent differences between subgroups with and without myocardial dysfunction.

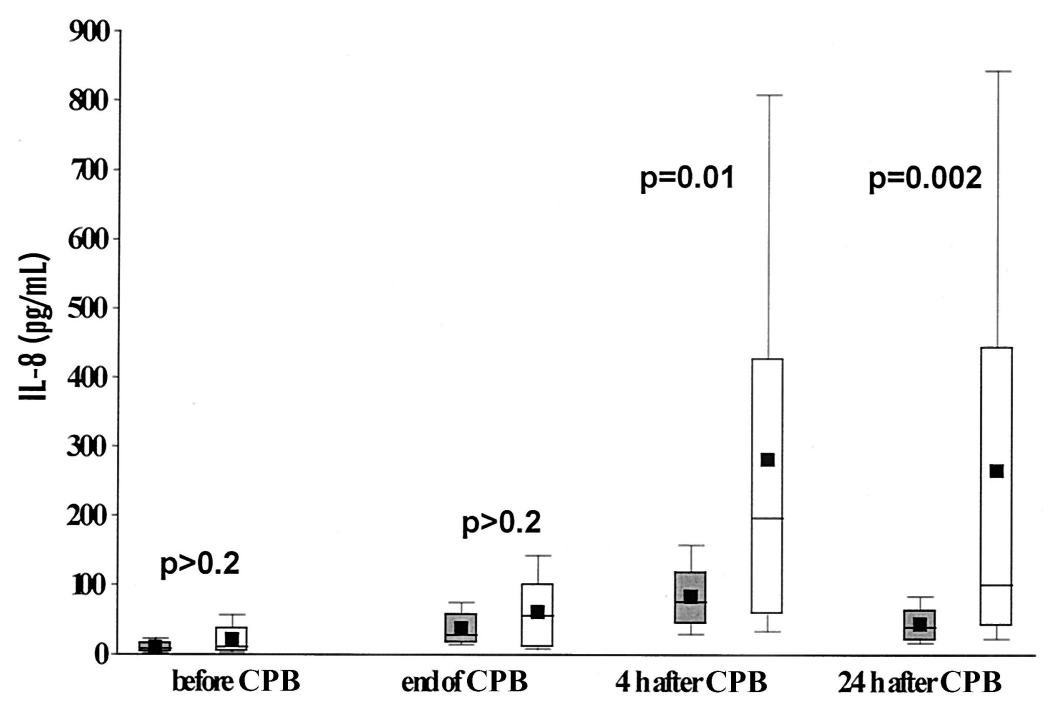

Figure 4. IL-8 levels related to presence (white bars, $\mathrm{n}=11$ ) and absence (shaded bars, $\mathrm{n}=52$ ) of myocardial dysfunction after CPB in 63 patients. Values expressed as mean (data points), median (horizontal lines), interquartile ranges (bars), and 10th and 90th percentiles (error bars). $P$ values represent differences between subgroups with and without myocardial dysfunction.

$\mathrm{CPB}$ and aortic crossclamping (tolerance \pm 5 minutes) with respect to the predictive value of IL-6 levels 4 hours after the operation for the occurrence of myocardial dysfunction was possible for 7 pairs of patients with and without myocardial dysfunction. This analysis showed that IL-6 blood levels 4 hours after the operation tended to predict myocardial dysfunction within 24 hours after the operation $(P=$
.07 , odds ratio per $10 \mathrm{pg} / \mathrm{mL} 1.09,95 \%$ confidence interval $0.992-1.200)$.

\section{Discussion}

\section{Myocardial Dysfunction}

Our data are based on a large, homogeneous group of consecutive term neonates with transposition of the great 
arteries in whom preoperative, perioperative, and postoperative care was conducted according to standardized protocols. Perioperative myocardial dysfunction was prospectively evaluated by routinely available clinical examinations as restricted pump function observed by the responsible cardiac surgeon after coronary reperfusion and also as hypocontractility of one or both ventricles assessed by qualitative 2-dimensional echocardiography by experienced pediatric cardiologists. Standardized measurements such as systolic shortening fraction according to m-mode echocardiography were not routinely available because of limited transthoracal echolucency related to mechanical ventilation, sternotomy, wound dressings, or pacing wires. The reliability of our clinical criteria to evaluate myocardial dysfunction was confirmed by the fact that clinical outcome parameters such as AST levels, total inotropic support, delayed sternal closure, mechanical ventilation time, and in-hospital death were correlated with the occurrence of myocardial dysfunction.

\section{Release of Cardiac Troponin $T$}

In recent studies, cTnT and cardiac troponin I have been evaluated as indicative of perioperative myocardial damage in adults after coronary artery bypass grafting. ${ }^{25,26}$ In pediatric cardiovascular surgery, perioperative myocardial dysfunction depends on the surgical procedure itself as well as on intraoperative factors such as durations of $\mathrm{CPB}$, aortic crossclamping, and circulatory arrest. Preliminary data indicate that $\mathrm{cTnT}$ values shortly after surgery for congenital heart disease are potentially useful prognostic indicators of postoperative recovery. ${ }^{2-5,27}$ In these studies, however, data were from children at different ages and with different types of heart defects. Our study reports for the first time on correlations of cTnT values with clinical outcome in a large, homogeneous group of neonates after cardiac surgery.

Our data demonstrate that the arterial switch operation in neonates is related to myocardial cell damage, with loss of cTnT. In addition, our results clearly show that myocardial dysfunction, as assessed according to our definition, is associated with higher cTnT release, suggesting a higher degree of myocardial cell damage in these patients. On multivariable analysis, however, cTnT elevation could not be evaluated as an independent predictive variable of early postoperative myocardial dysfunction in our neonatal population. Cardiac regulator proteins cTnT and cardiac troponin I have been accepted as specific serum markers of irreversible cardiomyocyte injury, but it is not clear whether they also represent a suitable marker of subtle, reversible injury. ${ }^{28}$ The latter is suggested by a recent animal study of our group, ${ }^{7}$ which showed that levels of circulating cardiac troponins are not related to the percentage of necrotic or apoptotic myocardial cells. In our study cTnT values immediately after the operation were strongly correlated with those 4 and 24 hours after $\mathrm{CPB}$, probably reflecting early release of the cytosolic component of troponin followed by the later increase caused by slow degradation of myocardial cell myofibrils. ${ }^{29}$

\section{Production of the Proinflammatory Cytokines Interleukin 6 and 8}

A main purpose of this work was to assess whether enhanced synthesis of proinflammatory cytokines is associated with postoperative myocardial dysfunction in neonates. Proinflammatory cytokines are known to be mediators of myocardial cell damage ${ }^{18}$ and have been found to be related to postoperative damage to organs including the myocardium in a recent experimental study of our group. ${ }^{30}$ Cytokines are highly potent endogenous peptides capable of modulating cardiovascular function through various mechanisms, such as promoting ventricular remodeling, inducing contractile dysfunction, and uncoupling myocardial $\beta$-adrenergic receptors. ${ }^{31}$ Tumor necrosis factor $\alpha$, the prototype of harmful proinflammatory cytokines, has cytotoxic effects leading to cell membrane damage with gap formation, rupture, interstitial edema, and cell necrosis, ${ }^{7,32}$ as well as the capability of inducing apoptosis. ${ }^{16}$ During cardiac surgery, the myocardium has been found to be not only a target organ for proinflammatory cytokines but also a local site of production of circulating cytokines such as tumor necrosis factor $\alpha$, IL-6, and IL-8, ${ }^{20,32,33}$ all of which are involved in neutrophil and endothelial cell activation during CPB. In a recent experimental study of our group, higher intramyocardial tumor necrosis factor $\alpha$ synthesis was associated with extensive myocardial lesions. ${ }^{7}$

In clinical studies on adults, proinflammatory cytokines IL-6 and IL-8 were found to be associated with postoperative myocardial ischemia and segmental wall abnormalities $^{18}$ and with the acute-phase response accompanying myocardial infarction, reflecting the extent of early myocardial damage. ${ }^{19,20} \mathrm{IL}-6$ was found to be produced in cardiac myocytes during ischemia and reperfusion in patients undergoing coronary bypass surgery. ${ }^{20}$ In children, IL-6 levels were found to be elevated in the early postoperative period, ${ }^{11,12}$ correlated with the duration of inotropic support. ${ }^{34}$ IL-8 is also suggested to be produced in the ischemic myocardium. ${ }^{35}$ In children IL-8 levels are elevated early after cardiac surgery and are correlated with the duration of CPB. ${ }^{10,13}$

In our homogeneous group of neonates, significant elevations of IL-6 and IL-8 levels relative to preoperative values immediately and 4 and 24 hours after surgery in patients with and without myocardial dysfunction, and their correlations with duration of operation variables, confirmed the role of CPB and myocardial ischemia on the induction of these proinflammatory cytokines. In patients with myocardial dysfunction, IL-6 plasma levels tended to be higher immediately after CPB and were significantly higher 4 hours after the operation than in those without myocardial 
dysfunction. This fact, as well as our observation of a significant correlation between proinflammatory cytokine levels and cTnT values in the early postoperative period, support the assumption that proinflammatory cytokines may contribute to myocardial damage and therefore to depressed myocardial function. ${ }^{31}$

\section{Limitations}

The causal relationship between uncontrolled synthesis of proinflammatory cytokines and myocardial damage and dysfunction could only be definitively demonstrated in trials with cytokine-blocking or -inhibiting agents. Therefore the association between elevated plasma levels of proinflammatory cytokines and myocardial dysfunction, as shown in this study, needs to be confirmed by further investigation.

\section{Conclusions}

Cardiac operations in neonates induce the production of the proinflammatory cytokines IL-6 and IL-8. The latter may be related to myocardial cell damage, as indicated by cTnT release, and to postoperative myocardial dysfunction. The cTnT level is a useful indicator of myocardial cell damage but does not allow prediction of the occurrence of early postoperative myocardial dysfunction in this age group.

\section{References}

1. Wernovsky G, Wypij D, Jonas RA, Mayer JE, Hanley FL, Hickey PR, et al. Postoperative course and hemodynamic profile after the arterial switch operation in neonates and infants: a comparison of low-flow cardiopulmonary bypass and circulatory arrest. Circulation. 1995;92: 2226-35

2. Lipshultz SE, Rifai N, Sallan SE, Lipsitz SR, Dalton V, Sacks DB, et al. Predictive value of cardiac troponin $\mathrm{T}$ in pediatric patients at risk for myocardial injury. Circulation. 1997;96:2641-8.

3. Taggart DP, Hadjinikolas L, Hooper J, Albert J, Kemp M, Hue D, et al. Effects of age and ischemic times on biochemical evidence of myocardial injury after pediatric cardiac operations. J Thorac Cardiovasc Surg. 1997;113:728-35.

4. Hirsch R, Dent CL, Wood MK, Huddleston CB, Mendeloff EN, Balzer DT, et al. Patterns and potential value of cardiac troponin I elevations after pediatric cardiac operations. Ann Thorac Surg. 1998; 65:1394-9.

5. Immer FF, Stocker F, Seiler AM, Pfammatter JP, Bachmann D, Printzen G, et al. Troponin-I for prediction of early postoperative course after pediatric cardiac surgery. J Am Coll Cardiol. 1999;33: $1719-23$

6. Meldrum DR. Tumor necrosis factor in the heart. Am $J$ Physiol. 1998;274(3 Pt 2):R577-95.

7. Vazquez-Jimenez JF, Qing M, Hermanns B, Klosterhalfen B, Woltje M, Chakupurakal R, et al. Moderate hypothermia during cardiopulmonary bypass reduces myocardial cell damage and myocardial cell death related to cardiac surgery. J Am Coll Cardiol. 2001;38:1216-23.

8. Seghaye MC, Duchateau J, Grabitz RG, Nitsch G, Marcus C, Messmer BJ, et al. Complement, leukocytes, and leukocyte elastase in full-term neonates undergoing cardiac operation. J Thorac Cardiovasc Surg. 1994;108:29-36.

9. Seghaye MC, Grabitz RG, Duchateau J, Busse S, Dabritz S, Koch D, et al. Inflammatory reaction and capillary leak syndrome related to cardiopulmonary bypass in neonates undergoing cardiac operations. J Thorac Cardiovasc Surg. 1996;112:687-97.
10. Finn A, Naik S, Klein N, Levinsky RJ, Strobel S, Elliott M. Interleukin-8 release and neutrophil degranulation after pediatric cardiopulmonary bypass. $J$ Thorac Cardiovasc Surg. 1993;105:234-41.

11. Butler J, Pathi VL, Paton RD, Logan RW, MacArthur KJ, Jamieson $\mathrm{MP}$, et al. Acute-phase responses to cardiopulmonary bypass in children weighing less than 10 kilograms. Ann Thorac Surg. 1996;62:53842.

12. Seghaye MC, Duchateau J, Grabitz RG, Jablonka K, Wenzl T, Marcus $\mathrm{C}$, et al. Influence of low-dose aprotinin on the inflammatory reaction due to cardiopulmonary bypass in children. Ann Thorac Surg. 1996; 61:1205-11.

13. Seghaye M, Duchateau J, Bruniaux J, Demontoux S, Bosson C, Serraf A, et al. Interleukin-10 release related to cardiopulmonary bypass in infants undergoing cardiac operations. J Thorac Cardiovasc Surg. 1996;111:545-53.

14. Finkel MS, Oddis CV, Jacob TD, Watkins SC, Hattler BG, Simmons RL. Negative inotropic effects of cytokines on the heart mediated by nitric oxide. Science. 1992;257:387-9.

15. Ungureanu-Longrois D, Balligand JL, Kelly RA, Smith TW. Myocardial contractile dysfunction in the systemic inflammatory response syndrome: role of a cytokine-inducible nitric oxide synthase in cardiac myocytes. J Mol Cell Cardiol. 1995;27:155-67.

16. Arstall MA, Sawyer DB, Fukazawa R, Kelly RA. Cytokine-mediated apoptosis in cardiac myocytes: the role of inducible nitric oxide synthase induction and peroxynitrite generation. Circ Res. 1999;85: 829-40.

17. Wan S, LeClerc JL, Vincent JL. Inflammatory response to cardiopulmonary bypass: mechanisms involved and possible therapeutic strategies. Chest. 1997;112:676-92.

18. Hennein HA, Ebba H, Rodriguez JL, Merrick SH, Keith FM, Bronstein $\mathrm{MH}$, et al. Relationship of the proinflammatory cytokines to myocardial ischemia and dysfunction after uncomplicated coronary revascularization. J Thorac Cardiovasc Surg. 1994;108:626-35.

19. Pannitteri G, Marino B, Campa PP, Martucci R, Testa U, Peschle C. Interleukins 6 and 8 as mediators of acute phase response in acute myocardial infarction. Am J Cardiol. 1997;80:622-5.

20. Sawa Y, Ichikawa H, Kagisaki K, Ohata T, Matsuda H. Interleukin-6 derived from hypoxic myocytes promotes neutrophil-mediated reperfusion injury in myocardium. J Thorac Cardiovasc Surg. 1998;116: 511-7.

21. Wan S, DeSmet JM, Barvais L, Goldstein M, Vincent JL, LeClerc JL. Myocardium is a major source of proinflammatory cytokines in patients undergoing cardiopulmonary bypass. $J$ Thorac Cardiovasc Surg. 1996;112:806-11.

22. Gittenberger-de Groot AC, Sauer U, Oppenheimer-Dekker A, Quagebeur J. Coronary arterial anatomy in transposition of the great arteries: a morphologic study. Pediatr Cardiol. 1989;4:15-24.

23. Panteghini M, Agnoletti G, Pagani F, Spandrio M. Cardiac troponin T in serum as marker for myocardial injury in newborns. Clin Chem. 1997;43:1455-7.

24. Seghaye MC, Heyl W, Grabitz RG, Schumacher K, Von Bernuth G, Rath W, et al. The production of pro- and anti-inflammatory cytokines in neonates assessed by stimulated whole cord blood culture and by plasma levels at birth. Biol Neonate. 1998;73:220-7.

25. Mair J, Larue C, Mair P, Balogh D, Calzolari C, Puschendorf B. Use of cardiac troponin I to diagnose perioperative myocardial infarction in coronary artery bypass grafting. Clin Chem. 1994;40:2066-70.

26. Carrier M, Pellerin M, Perrault LP, Solymoss BC, Pelletier LC. Troponin levels in patients with myocardial infarction after coronary artery bypass grafting. Ann Thorac Surg. 2000;69:435-40.

27. Kaplan S. Biochemical markers of myocardial injury in children. Circulation. 1997;96:2496-7.

28. Sobel BE, LeWinter MM. Ingenuous interpretation of elevated blood levels of macromolecular markers of myocardial injury: a recipe for confusion. J Am Coll Cardiol. 2000;35:1355-8.

29. Wu AH. Risk stratification of cardiac troponin in ischaemic and non-ischaemic cardiac diseases and procedures. Clin Biochem Rev. 2000;21:79-88.

30. Qing M, Vazquez-Jimenez JF, Klosterhalfen B, Sigler M, Schumacher 
$\mathrm{K}$, Duchateau J, et al. Influence of temperature during cardiopulmonary bypass on leucocyte activation, cytokine balance, and postoperative organ damage. Shock. 2001;15:372-7.

31. Blum A, Miller H. Role of cytokines in heart failure. Am Heart J. 1998;135:181-6.

32. Meldrum DR, Meng X, Dinarello CA, Ayala A, Cain BS, Shames $\mathrm{BD}$, et al. Human myocardial tissue $\mathrm{TNF} \alpha$ expression following acute global ischemia in vivo. J Mol Cell Cardiol. 1998;30:1683-9.

33. Dreyer WJ, Phillips SC, Lindsey ML, Jackson P, Bowles NE, Michael
$\mathrm{LH}$, et al. Interleukin 6 induction in the canine myocardium after cardiopulmonary bypass. J Thorac Cardiovasc Surg. 2000;120:25664.

34. Hövels-Gürich HH, Schumacher K, Vazquez-Jimenez JF, Qing M, Hüffmeier U, Buding B, et al. Cytokine balance in infants undergoing cardiac operation. Ann Thorac Surg. 2002;73:601-9.

35. Kanda T, Hirao Y, Oshima S, Yuasa K, Taniguchi K, Nagai R, et al. Interleukin-8 as a sensitive marker of unstable coronary artery disease. Am J Cardiol. 1996;77:304-7.

\section{JTCVS On-Line Manuscript Submission and Review}

\section{Please visit http://www.editorialmanager.com/jtcvs/}

Effective September 15, 2001, authors and reviewers may submit manuscripts and reviews electronically via Editorial Manager, our new Web-based system with full electronic submission, review, and status update capabilities.

As we move from paper to electronic submissions, the Editorial Office will make proxy submissions of all manuscripts accompanied by a diskette containing the electronic files of the text, tables, and figures. Editors, authors, and reviewers will receive automatic e-mails when significant events occur.

We strongly encourage all authors and reviewers to use Editorial Manager. Although we will continue to accommodate the submission of paper manuscripts for some months, our goal is to be completely electronic within 9 to 12 months.

All individuals currently in our database for whom we have e-mail addresses will receive via e-mail a system-assigned username and password that can be used to log in to the system without prior registration. All those not receiving the e-mail must register the first time they use the system.

As with any broad systemic change, the conversion to the new system will take some time to complete. We ask your patience as we replace our in-office database with the new system. We also encourage you to take advantage of the speed and efficiency that the new system will provide for us all: editor, author, reviewer, and publisher. 